Saudi Journal of Oral and Dental Research

Abbreviated Key Title: Saudi J Oral Dent Res

ISSN 2518-1300 (Print) |ISSN 2518-1297 (Online)

Scholars Middle East Publishers, Dubai, United Arab Emirates

Journal homepage: https://saudijournals.com

\title{
Association between Systemic Diseases and Endodontics: A Systematic Review
}

Dr. Ahmed A. Madfa*, Dr. Adhwaa Fahad Algharbi, Dr. Muneera Ali Alqufeye, Dr. Reem Khaled Almuslumani, Dr. Abdulrahman Mansour Alsulayhim, Dr. Latifah Lafy Alenezi, Dr. Amjad Eid Alanazi, Dr. Fatima Sultana

Department of Dentistry, Riyadh, Saudi Arabia

DOI: $10.36348 /$ sjodr.2020.v05i12.007 $\quad$ | Received: 03.12.2020 | Accepted: 16.12 .2020 | Published: 18.12 .2020

*Corresponding author: Dr. Ahmed A. Madfa

\section{Abstract}

'Endodontics' is the branch of dentistry that deals with the tissues around the pulp and roots of a tooth. The treatment of the soft pulp tissue inside the tooth are included in the Endodontic treatment commonly called as the root canal treatment. The exposure of the pulp caused due to caries or dental trauma may result in bacterial colonization in the pulp tissue resulting in Endodontic infection. The dental procedures like the endodontic treatment (root canal treatment), tooth extraction, root scaling, bilateral tonsillectomy and periodontal surgery may cause Bacteremia and is well documented in the literature. The Bacteremia can cause many fatal problems like Heart valve deformity, Endothelial cell damage to valve, Platelet aggregation on valve, Non-bacterial thrombotic endocarditis (NBTE), Bacterial adherence to NBTE, Bacterial colonization of valve NBTE, Bacterial endocarditis. The main aim of this research was to review the literature related to the relationship between the systemic diseases and endodontics. The principal investigator of this research conducted a systemic comprehensive literature review independently using Web of Science, Scopus, Pubmed Central, Medline, EMBASE, and Cochrane web databases. The 16 articles that followed all the required criteria were selected, studied and evaluated. In the current study, the literature related to the association of chronic systemic disease and endodontic diseases were studied. With this we can conclude that a probable co-relation occurs between the chronic systemic diseases and the endodontic diseases.

Keywords: Systemic diseases, endodontic diseases, Endodontics, root canal treatment, Periapical Periodontitis, Apical Periodontitis.

Copyright (C) 2020 The Author(s): This is an open-access article distributed under the terms of the Creative Commons Attribution 4.0 International License (CC BY-NC 4.0) which permits unrestricted use, distribution, and reproduction in any medium for non-commercial use provided the original author and source are credited.

\section{INTRODUCTION}

Endodontics name was taken from Greek words; 'Endo' meaning 'inside' and 'odont' means 'tooth'. 'Endodontics' is the branch of dentistry that deals with the tissues around the pulp and roots of a tooth. The treatment of the soft pulp tissue inside the tooth is included in the Endodontic treatment commonly called as the root canal treatment. The exposure of the pulp caused due to caries or dental trauma may result in bacterial colonization in the pulp tissue resulting in Endodontic infection. The outcome of the Endodontic infection results in apical periodontitis that is characterized by intra-canal bacterial infection that may result in further degradation of the bone. The immune system of the host produces cytokines at the site of infection that may cause inflammation and bone resorption [1].
The infection by the pathogenic microorganisms in the oral cavity could trigger the spread of pathogens to distant sites of the bodies. Several studies reported that the oral cavity infections could act as a risk factor for many systemic diseases. The teeth with dental plaque may contain millions of bacteria, that are anaerobic and gram negative type [2]. The dental procedures like the endodontic treatment (root canal treatment), tooth extraction, root scaling, bilateral tonsillectomy and periodontal surgery may cause Bacteremia and is well documented in the literature. Bacteremia is the condition that is the presence of bacteria in blood. Bacteremia was seen to be $100 \%$ in the patients that had undergone dental extraction. Several studies reported the release of bacteria after the dental procedures into the blood stream that reached the heart, lungs and other vital organs. The transient Bacteremia caused due to dental procedures after the oral infections may result in metastatic infection, metastatic injury and metastatic inflammation. 
One of the most common infections of the oral cavity is periodontal disease. The inflammation and destruction of gingiva, root cementum, periodontal ligament and alveolar bone are associated with the periodontal disease. The gram-negative, anaerobic bacterium that is found in the dental plaque is known to cause the periodontal disease [3].

Mostly bacteria like Actinobacillus actinomycetemcomitans, Porphyromonas gingivalis, and Bacteroides forsythus are associated with periodontitis. Untreated periodontitis may lead to the bone loss and apical migration of the tissue leading to formation of periodontal pockets. The periodontitis causes Bacteremia which leads to development of many bio-reactions in the body like: Hyper-inflammation, Hyperactivity, release of bacterial products like endotoxins, release of inflammatory products like cytokines, Hyper coagulation and loss of teeth [4]. All these bio-reactions can lead to vascular pathology that ultimately results in the development of cardiovascular diseases. The C-reactive protein (CRP) and haptoglobin significantly decline after the periodontal treatment. The bacteria in the blood stream may also cause the infection of the heart valves/endothermic tissues of the heart that is called endocarditis. In relation to the dental diseases and therapy, the infective endocarditis is highly infectious, fatal and severe systemic disease. The Bacteremia can cause many fatal problems like Heart valve deformity, Endothelial cell damage to valve, Platelet aggregation on valve, Non-bacterial thrombotic endocarditis (NBTE), Bacterial adherence to NBTE, Bacterial colonization of valve NBTE, Bacterial endocarditis [4].

It has been reported that severe diabetes mellitus is seen in patients with severe periodontal disease. Diabetes mellitus is a risk factor for periodontitis. The diabetic patients are more likely to get periodontal disease when compared with the nondiabetic patients [5].

In response to the bacterial infection the immune system of the host releases neutrophils as the first line defence against the micro-organisms [6]. In the Diabetic patients, the functioning and bactericidal activity of the neutrophils is impaired; many findings suggest that the diabetes cause modulations in the hyper-inflammatory state in the immune system of the host [7]. The periodontal inflammation and the periodontal disease can have a negative impact in patients with type II diabetes by elevating the proinflammatory mediators that may cause bone destruction. The high inflammatory cytokines profile can be seen in patients with uncontrolled type II diabetes. The Gingival crevicular fluid (GCF) levels are high in the uncontrolled diabetic patient when compared with the controlled diabetic patient [8]. Diabetes mellitus is one of the most prevalent diseases that occur in medically compromised dental patients.
The advanced form of endodontic infection or the endodontic inflammation is the formation of periapical abscess that is comorbid with the hypertensive patients [9].

Several studies are proposed to understand the relationship between the endodontic diseases and the systemic diseases. In the present study, the literature is reviewed to understand the connection between them.

\section{AIM AND OBJECTIVES}

The main aim of this research was to review the literature related to the relationship between the systemic diseases and endodontics. This can be attained by:

- Carrying out an online search of databases for the literature related to systemic diseases and endodontics.

- Systematically reviewing the literature available on Web of Science, Pubmed Central, Medline, Scopus, Embase, Google Scholar, etc.

- Identifying the complications related to the endodontic treatment and the chronic systemic diseases.

- Determining the indications of the endodontic diseases on different parts of the body.

- Identifying the risk factors of systemic diseases.

\section{METHODOLOGY}

An online based, web search was made using various databases like Web of Science, Medline, Pubmed Central, Embase, Scopus, Google Scholar, Directory of Open Access Journals (DOAJ), and Cochrane electronic databases. The systematic review of literature was carried out in English language. In the initial term of reviewing, no filters were applied to make sure all the studies are available for successive screening. Later on filters like human and animal studies, only English language studies were added. The literature review was conducted by studying about 16 articles related to the endodontics and its relation with systemic diseases.

\section{MESH TERMS USED}

Diabetes Mellitus OR Diabetes OR Diabetic OR Hyperglycaemia, AND Endodontics, Periapical Periodontitis, Periapical Diseases, Apical Periodontitis, Periradicular Lesion, Periapical Radiolucency, Radiolucent Periapical Lesion, Root Canal Treatment, Root Canal Preparation, Root Canal Therapy, Root Filled Teeth, Endodontically Treated Teeth.

\section{TIME LINE OF STUDY}

The research was done in a time range of 6 months to study and review all the literature and prepare the manuscript. 


\section{RESULTS}

A total of 526 articles were found on the online web databases, about 52 articles were excluded from the study with children studies. 112 articles were screened by removing other languages than English articles. From the 362 remaining articles around 159 articles were filtered that were incomplete. The further assessment of the 203 articles, 187 articles were removed that had only the abstract. The 16 articles that followed all the required criteria were selected, studied and evaluated.

Brito et al. [10], in the year 2003 studied the Human beings and understood the relationship between Periradicular lesions and Diabetes. Iwama et al. [11], in the year 2003 studied the Rats and found Bone loss, and apical periodontitis due to Diabetes. Segura-egea et al. [13] conducted a study in 2005 on Human beings and concluded the presence of Periapical radiolucencies due to Diabetes. Caplan et al. [14] in the year 2006 carried a study on the Human beings and found the relation between the chronic periodontal inflammation and cardiovascular diseases. Schulze et al. [15] in 2007 studied Human beings and found apical periodontitis to increase in patients with Diabetes. Segura-egea et al. [16] in the year 2010 conducted a study on Human beings to study the Endodontic infection and its association with the cardiovascular diseases in patients. López-lópez et al. [17] in 2011 studied Human beings and confirmed that the Periapical status linked with type II Diabetes. Pasqualini et al. [18] in 2012 made a study on Human beings and classified the connection between apical periodontitis (AP) and cardiovascular diseases. Cintra et al. [19] in the year 2013 carried out an experimental study on Rats and observed a relation between apical periodontitis, bone resorption and Diabetes in the rats. Costa et al. [20] in 2014 studied the Human beings to report a relation between chronic apical periodontitis and the cardiovascular disease. Gomes-filho et al. [21] in the year 2015 conducted an experimental study on Rats and observed a Progressive apical periodontitis in those that were suffering with Hypoestrogenia. An et al. [22] in 2016 carried a study on Human beings and reported a connection between apical periodontitis (AP) and the cardiovascular disease.

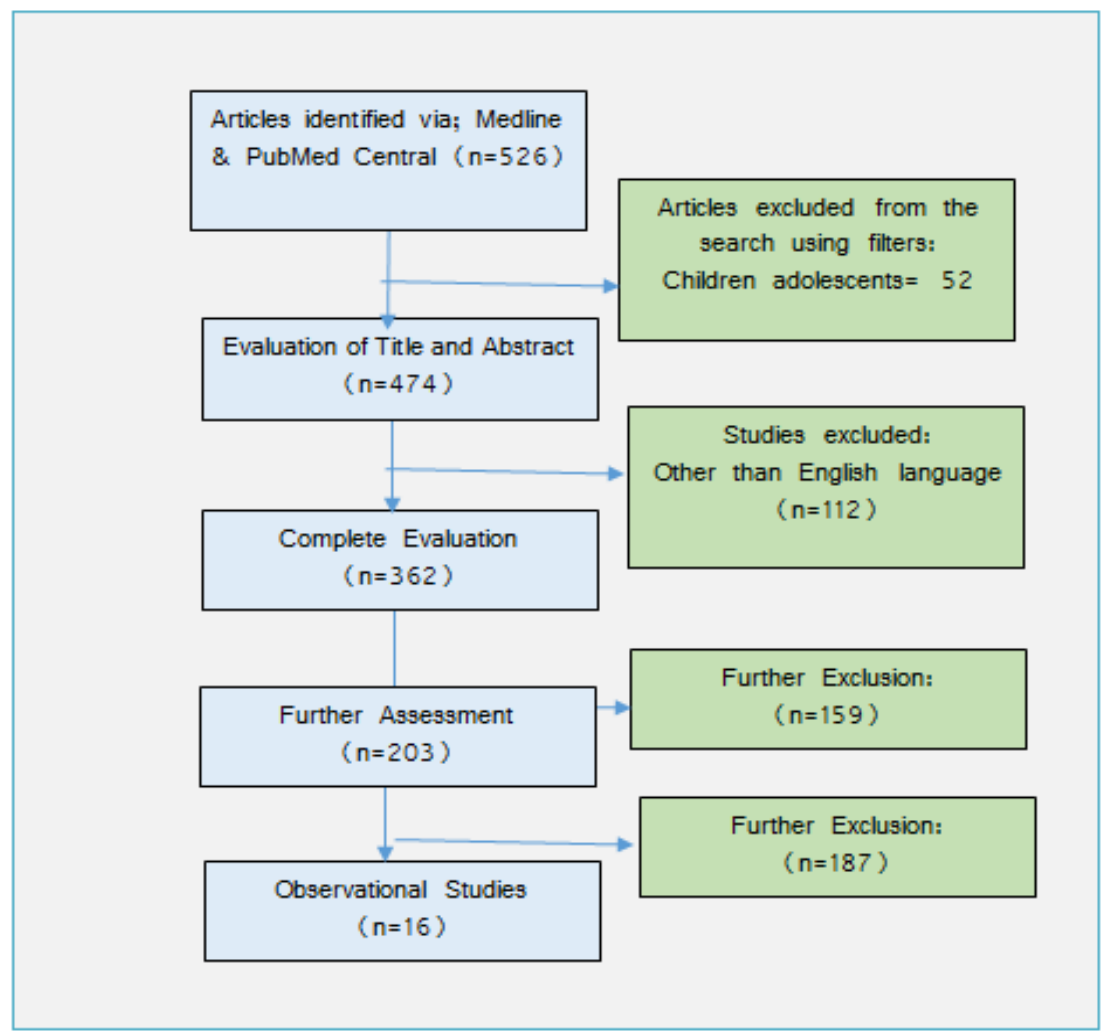

Arya et al. [23] in the year 2017conducted a study on Human beings and found Negative periapical healing in patients suffering with Diabetes. Samuel et al. [24] in 2018 carried out an experimental study on the Rats and found Apical periodontitis (AP) in rats with Increased leukocyte and lymphocyte levels in the blood. E. Laukkanen et al. [25] in the year 2019 conducted a study on Human beings and reported the Apical periodontitis (AP) in patients suffering with Diabetes and cardiovascular diseases. Anita Aminoshariae et al. [26] conducted a study in the year 2020 on the Human beings and reported Endodontic pathosis in patients suffering with Diabetes mellitus, cardiovascular disease and specific other systemic diseases. The literature from the year 2003 to 2020 was reviewed and all the articles were known to report a close connection between the systemic diseases and endodontics. 


\begin{tabular}{|c|c|c|c|c|}
\hline AUTHOR'S NAME & $\begin{array}{l}\text { YEAR OF } \\
\text { STUDY }\end{array}$ & $\begin{array}{l}\text { STUDY } \\
\text { CONDUCTED ON }\end{array}$ & $\begin{array}{l}\text { ENDODONTIC } \\
\text { PROBLEMS }\end{array}$ & $\begin{array}{l}\text { SYSTEMIC } \\
\text { DISEASES }\end{array}$ \\
\hline Brito et al. [10] & 2003 & Human beings & Periradicular lesions & Diabetes \\
\hline Iwama et al. [11] & 2003 & Rats & $\begin{array}{l}\text { Bone loss, apical } \\
\text { periodontitis }\end{array}$ & Diabetes \\
\hline Segura-egea et al. [12] & 2005 & Human beings & Periapical radiolucencies & Diabetes \\
\hline Caplan et al. [13] & 2006 & Human beings & $\begin{array}{l}\text { Chronic periodontal } \\
\text { inflammation }\end{array}$ & $\begin{array}{l}\text { Cardiovascular } \\
\text { diseases }\end{array}$ \\
\hline Schulze et al. [14] & 2007 & Human beings & Apical periodontitis & Diabetes \\
\hline Segura-egea et al. [15] & 2010 & Human beings & Endodontic infection & $\begin{array}{l}\text { Cardiovascular } \\
\text { diseases }\end{array}$ \\
\hline López-lópez et al. [16] & 2011 & Human beings & Periapical status linked & Diabetes \\
\hline Pasqualini et al. [17] & 2012 & Human beings & Apical periodontitis (ap) & $\begin{array}{l}\text { Cardiovascular } \\
\text { diseases }\end{array}$ \\
\hline Cintra et al. [18] & 2013 & Rats & $\begin{array}{l}\text { Apical periodontitis bone } \\
\text { resorption }\end{array}$ & Diabetes \\
\hline Costa et al. [19] & 2014 & Human beings & $\begin{array}{l}\text { Chronic apical } \\
\text { periodontitis }\end{array}$ & Cardiovascular disease \\
\hline Gomes-filho et al. [20] & 2015 & Rats & $\begin{array}{l}\text { Progressive apical } \\
\text { periodontitis }\end{array}$ & Hypoestrogenia \\
\hline An et al. [21] & 2016 & Human beings & Apical periodontitis (ap) & Cardiovascular disease \\
\hline Arya et al. [22] & 2017 & Human beings & $\begin{array}{l}\text { Negative periapical } \\
\text { healing }\end{array}$ & Diabetes \\
\hline Samuel et al. [23] & 2018 & Rats & Apical periodontitis (ap) & $\begin{array}{l}\text { Increase leukocyte and } \\
\text { lymphocyte levels in } \\
\text { the blood }\end{array}$ \\
\hline E. Laukkanen et al. [24] & 2019 & Human beings & Apical periodontitis (ap) & $\begin{array}{l}\text { Diabetes and } \\
\text { cardiovascular } \\
\text { diseases }\end{array}$ \\
\hline $\begin{array}{l}\text { Anita Aminosharriae et } \\
\text { al. [25] }\end{array}$ & 2020 & Human beings & Endodontic pathosis & $\begin{array}{l}\text { Diabetes mellitus, } \\
\text { cardiovascular disease } \\
\text { and specific other } \\
\text { systemic diseases }\end{array}$ \\
\hline
\end{tabular}

\section{DISCUSSION}

The oral cavity is home for many microorganisms like bacteria, viruses, fungi and protozoans. These microbes interact among themselves and also the host leading to the good health or disease in the host. It was reported that oral micro-organisms play a vital role in the progression or etiology of several chronic systemic diseases. In the oral cavity, the microorganisms cause dental caries, dental plaque, periodontitis, gingivitis, endodontic infections and also oral cancers. The most prevalent pathologies that are associated with the oral microbes are: systemic diseases, infections of various body parts, cardiovascular diseases, Type II Diabetes, adverse pregnancy outcomes. The risk factor for the development of coronary heart diseases and type II diabetes is the association of cluster factor commonly referred as metabolic syndrome (MetS). Many studies that were done on understanding the relation between the endodontic diseases and the systemic diseases reported a connection between them. The infectious and chronic inflammatory disease of the oral cavity is the periodontal disease and is a known potential risk factor for causing several cardiovascular diseases, respiratory disorders, pregnancy adverse outcomes, osteoporosis and Type II Diabetes. The periodontal diseases are know to spread locally and cause metastatic spread and immunological cross reactivity of the infection. It was also reported that the presence of the oral inflammatory lesions were known to increase and elevate the inflammatory systemic responses in the body of the patient.

The aim of the present study was to understand the connection between the metabolic diseases and the endodontic diseases. After clearly understanding the relation, we can control the occurrence of chronic metabolic diseases by following proper oral hygiene and plaque control. The principal investigator of this research conducted a systemic comprehensive literature review independently using Web of Science, Pubmed Central, and Medline, EMBASE, and Cochrane web databases. The investigator studied all the relevant articles related to the association between systemic diseases and Endodontic diseases. About 16 articles met the inclusion criteria for the study and had moderate to 
high level risk of bias. The scientific evidence of all the articles studied showed a relation between the varied systemic diseases and its endodontic outcomes. This systematic review suggests a co-relation between the endodontic and the chronic systemic disorders.

V. I. Haraszthy et al. [27] reported the presence of atheroma plaque (about 42\%) in the inner wall of the artery in patients suffering with periodontal diseases. Deshpande et al. [28] reported the pathogens of the gingivitis in mother bovine to transfer into the heart of the foetal bovine. Potempa et al. [29] confirmed in this study that the pathogens in the oral cavity releases proteolytic enzymes into the blood that activates the $\mathrm{C}$ protein, Blood factor $\mathrm{X}$, and prothromin in the host leading to intra-vascular clot formation. S. Al-Mubarak et al. [30] reported the atheroma formation by the stimulation of the liver to produce $\mathrm{C}$ reactive protein (CRP) after a periodontal infection.

It was also reported by Chauncey $\mathrm{H} \mathrm{H}$ et al. [31], that the oral infections may cause the loss of teeth that may result in edentulous condition. The edentate patients may have issues with chewing hard objects that may have certain nutritional value leading to improper nutrient supply to the body. To overcome this patient may opt for high calorie food with lots of fat that may result in the increase of cholesterol levels in the body and acts as a potential risk factor for cardiovascular diseases. Drangsholt et al. [6] concluded the incidence of endocarditis (infection of endocardium of heart) in patients with periodontal or dental diseases. Limeback et al. [33] reported an association between the poor oral hygiene and pneumonia aspiration in elder patients. Scannapieco et al. [34] reported the presence of higher oral index scores in individuals with respiratory diseases when compared with those individuals without respiratory diseases. Many studies showed an incidence of increased rate of amniotic infection and chorioamniotitis leading to pre-term birth in mothers with periodontal diseases. The pre-term birth infant's mothers had significantly worse periodontal disease when compared to the normal weight infant's mothers. Offenbacher et al. [35] in his study concluded that the mother has a pre-term delivery resulting in low birth weight infant due to the presence of periodontal disease in them. Grossi and Genco et al. [34] reported that the severity of Diabetes increases when the infection of the periodontal infections increases. Rudranaik et al. [35] concluded in his research that the Diabetic patients with chronic apical periodontitis have delayed healing when compared to the non-diabetic patients. Many of these go along with our main aim of study to understand the relation between endodontics and systemic disease.

\section{CONCLUSION}

The oral cavity acts as a harbour to varied microbes forming a biofilm that is referred to as dental plaque. The dental plaque can lead to the formation of caries, several endodontic infections and periodontitis.
If not treated properly the oral infections can spread to the other tissues and internal vital organs causing several systemic diseases like cardiovascular diseases, respiratory diseases, rheumatoid arthritis, Type II Diabetes, renal infections, vaginal infections and more. In the current study, the literature related to the association of chronic systemic disease and endodontic diseases were studied. With this we can conclude that a probable co-relation occurs between the chronic systemic diseases and the endodontic diseases. Further studies need to be carried out to understand the role of endodontic infections in the etiology and prevalence of systemic diseases.

\section{ETHICAL CONSIDERATIONS Compliance with ethical standards}

Ethical approval: This proposal contains survey studies with human participants performed by any of the authors.

Conflict of interest: The authors do not have any commercial associations that might pose or create a conflict of interest with information presented in this communication. No intramural or extramural funding supported any aspect of this work.

\section{REFERENCES}

1. Asikainen, S., \& Alaluusua, S. (1993). Bacteriology of dental infections. European heart journal, 14, 43.

2. Beck, J., Garcia, R., Heiss, G., Vokonas, P. S., \& Offenbacher, S. (1996). Periodontal disease and cardiovascular disease. Journal of periodontology, 67, 1123-1137.

3. Bonten, M. J., Gaillard, C. A., van Tiel, F. H., Smeets, H. G., van der Geest, S., \& Stobberingh, E. E. (1994). The stomach is not a source for colonization of the upper respiratory tract and pneumonia in ICU patients. Chest, 105(3), 878-884.

4. Debelian, G. J., Olsen, I., \& Tronstad, L. (1995). Bacteremia in conjunction with endodontic therapy. Dental Traumatology, 11(3), 142-149.

5. Debelian, G. J., Olsen, I., \& Tronstad, L. (1998). Anaerobic bacteremia and fungemia in patients undergoing endodontic therapy: an overview. Annals of Periodontology, 3(1), 281-287.

6. Drangsholt, M. (1992). Association of dental procedures and infective endocarditis: a metaanalysis (Doctoral dissertation, University of Washington).

7. Carroll, G. C., \& Sebor, R. J. (1980). Dental flossing and its relationship to transient bacteremia. Journal of periodontology, 51(12), 691-692.

8. Childs III, W. C., \& Gibbons, R. J. (1990). Selective modulation of bacterial attachment to oral epithelial cells by enzyme activities associated with poor oral hygiene. Journal of periodontal research, 25(3), 172178.

9. Darveau, R. P., Tanner, A., \& Page, R. C. (1997). The microbial challenge in periodontitis. Periodontology 2000, 14(1), 12-32. 
10. Britto, L. R., Katz, J., Guelmann, M., \& Heft, M. (2003). Periradicular radiographic assessment in diabetic and control individuals. Oral Surgery, Oral Medicine, Oral Pathology, Oral Radiology, and Endodontology, 96(4), 449-452.

11. Iwama, A., Nishigaki, N., Nakamura, K., Imaizumi, I., Shibata, N., Yamasaki, M., \& Kapila, Y. (2003). The effect of high sugar intake on the development of periradicular lesions in rats with type 2 diabetes. Journal of dental research, 82(4), 322-325.

12. Segura- Egea, J. J., Jiménez- Pinzón, A., RíosSantos, J. V., Velasco- Ortega, E., Cisneros- Cabello, R., \& Poyato- Ferrera, M. (2005). High prevalence of apical periodontitis amongst type 2 diabetic patients. International endodontic journal, 38(8), 564569.

13. Caplan, D. J., Chasen, J. B., Krall, E. A., Cai, J., Kang, S., Garcia, R. I., \& Beck, J. D. (2006). Lesions of endodontic origin and risk of coronary heart disease. Journal of dental research, 85(11), 996-1000.

14. Schulze, A., Schönauer, M., \& Busse, M. (2007). Sudden improvement of insulin sensitivity related to an endodontic treatment. Journal of periodontology, 78(12), 2380-2384.

15. Segura-Egea, J. J., Jimenez-Moreno, E., CalvoMonroy, C., Ríos-Santos, J. V., Velasco-Ortega, E., Sánchez-Domínguez, B., \& Llamas-Carreras, J. M. (2010). Hypertension and dental periapical condition. Journal of endodontics, 36(11), 1800-1804.

16. López-López, J., Jané-Salas, E., Estrugo-Devesa, A., Velasco-Ortega, E., Martín-González, J., \& SeguraEgea, J. J. (2011). Periapical and endodontic status of type 2 diabetic patients in Catalonia, Spain: a crosssectional study. Journal of endodontics, 37(5), 598601.

17. Pasqualini, D., Bergandi, L., Palumbo, L., Borraccino, A., Dambra, V., Alovisi, M., ... \& Scotti, N. (2012). Association among oral health, apical periodontitis, CD14 polymorphisms, and coronary heart disease in middle-aged adults. Journal of endodontics, 38(12), 1570-1577.

18. Cintra, L. T. A., da Silva Facundo, A. C., Azuma, M. M., Sumida, D. H., Astolphi, R. D., Bomfim, S. R. M., ... \& Gomes-Filho, J. E. (2013). Pulpal and periodontal diseases increase triglyceride levels in diabetic rats. Clinical oral investigations, 17(6), 15951599.

19. Costa, T. H. R., de Figueiredo Neto, J. A., de Oliveira, A. E. F., e Maia, M. D. F. L., \& de Almeida, A. L. (2014). Association between chronic apical periodontitis and coronary artery disease. Journal of endodontics, 40(2), 164-167.

20. Gomes- Filho, J. E., Wayama, M. T., Dornelles, R. C. M., Ervolino, E., Yamanari, G. H., Lodi, C. S., ... \& Cintra, L. T. A. (2015). Raloxifene modulates regulators of osteoclastogenesis and angiogenesis in an oestrogen deficiency periapical lesion model. International endodontic journal, 48(11), 1059-1068.
21. An, G. K., Morse, D. E., Kunin, M., Goldberger, R. S., \& Psoter, W. J. (2016). Association of radiographically diagnosed apical periodontitis and cardiovascular disease: a hospital records-based study. Journal of endodontics, 42(6), 916-920.

22. Arya, S., Duhan, J., Tewari, S., Sangwan, P., Ghalaut, V., \& Aggarwal, S. (2017). Healing of apical periodontitis after nonsurgical treatment in patients with type 2 diabetes. Journal of endodontics, 43(10), 1623-1627.

23. Samuel, R. O., Gomes-Filho, J. E., Azuma, M. M., Sumida, D. H., de Oliveira, S. H. P., Chiba, F. Y., ... \& Cintra, L. T. A. (2018). Endodontic infections increase leukocyte and lymphocyte levels in the blood. Clinical Oral Investigations, 22(3), 1395-1401.

24. Laukkanen, E., Vehkalahti, M. M., \& Kotiranta, A. K. (2019). Impact of systemic diseases and tooth- based factors on outcome of root canal treatment. International endodontic journal, 52(10), 1417-1426.

25. Aminoshariae, A., Kulild, J., \& Fouad, A. F. (2020). The impact of cardiovascular disease and endodontic outcome: a systematic review of longitudinal studies. Clinical Oral Investigations, 1-7.

26. Haraszthy, V. I., Zambon, J. J., Trevisan, M., Shah, R., Zeid, M., \& R. J. Genco, J. Dent. Res. Spec. Iss. 77, 666, abstr. 273, 1998

27. Deshpande, R. G., Khan, M. B., \& Genco, C. A. (1998). Invasion of aortic and heart endothelial cells byporphyromonas gingivalis. Infection and immunity, 66(11), 5337-5343.

28. Potempa, J., Imamura, T., \& J. (1999). Travis, J. Dent. Res. Spec. Iss. 78, 180, abstr. 593, 1999

29. Al-Mubarak, S., Ciancio, S. G., Al-Suwyed, A., Hamouda, W., \& P. Dandona, J. (1998). Dent. Res. Spec. Iss. 77, p. 1030, abstr. 3192.

30. Chauncey, H.H., Muench, M.E., Kapur, K.K., Wayler, A.H. (1984). The effect of the loss of teeth on diet and nutrition. Int Dent J, 34:98-104.

31. Limeback, H. (1988). The relationship between oral health and systemic infections among elderly residents of chronic care facilities: A review 1. Gerodontology, 7(3- 4), 131-137.

32. Scannapieco, F. A., \& Mylotte, J. M. (1996). Relationships between periodontal disease and bacterial pneumonia. Journal of periodontology, 67, 1114-1122.

33. Offenbacher, S., Beck, J. D., Lieff, S., \& Slade, G. (1998). Role of periodontitis in systemic health: spontaneous preterm birth. Journal of Dental Education, 62(10), 852-858.

34. Grossi, S. G., \& Genco, R. J. (1998). Periodontal disease and diabetes mellitus: a two- way relationship. Annals of periodontology, 3(1), 51-61.

35. Rudranaik, S., Nayak, M., \& Babshet, M. (2016). Periapical healing outcome following single visit endodontic treatment in patients with type 2 diabetes mellitus. Journal of clinical and experimental dentistry, 8(5), e498. 